\title{
Temporal Reference
}

\author{
Alessandra Giorgi \\ $\mathrm{Ca}$ Foscari University of Venice, Italy
}

\section{Fabio Pianesi}

Bruno Kessler Foundation, Trento, Italy

1 Introduction

2 Tenses as sentential operators

3 Temporal entities

3.1 The syntax of tense

3.1.1 The cartographic approach

3.1.2 Stowell's approach

3.2 Sequence of tense

3.3 The double-access reading

3.4 Temporal adverbials

4 A non-referential approach

4.1 A-series versus B-series

4.2 Complex tenses

4.3 Sequence of tense

4.4 Taking stock of the A-series approach

5 Conclusion

\section{Introduction}

The foundational issues for a correct account of temporal talk in natural language appear uncontentious: we exploit an ontology countenancing temporal entities (time points, time intervals, and/or events) to serve as the referents of such phrases as at three or when John arrived, and of the variables appearing in temporal quantification: often, always, seldom, and so on. Those entities are organized in a natural sequence by the earlier than-later than relation, which also turns out to be useful in accounting for our intuitions about the meaning of tenses - for example, "past"

The Wiley Blackwell Companion to Syntax, Second Edition.

Edited by Martin Everaert and Henk van Riemsdijk.

(C) 2017 John Wiley \& Sons, Inc. Published 2017 by John Wiley \& Sons, Inc. 
contributes the fact that the relevant event or time is before the speech or utterance of interest - and of such phrases as John left after his sister entered. The resulting temporal structures seem so natural and intuitive that linguists almost never question them. All we have to do is use them to discover how temporal reference is managed by language.

However, another view about time in language (and time in general) has exercised scholars for years, originating from concerns expressed by philosophers. According to its proponents, we can - and actually must - dispense with temporal entities, hence with temporal reference. Our temporal talk cannot be analyzed on the model of objectual talk, by positing temporal entities ordered by the earlier than-later than relation from which, for instance, Thursday or May can draw their reference. The correct approach, it is maintained, requires taking the very idea of tensed thoughts and propositions seriously, which means that the latter are intrinsically tensed and that tense cannot be explained away by means of precedence.

Although not popular among linguists, such a view has been revived and sharpened by Ludlow (1999), whose proposal strikingly differs not only from "strictly" referential approaches, but from those based on so-called temporal logic too.

Preference for one account over the other has profound effects on linguistic theory. In one case, we expect to avail ourselves of the machinery made available to semantics and syntax by the referential view, which includes objectual quantification, referential anaphora, and the referential view of indexicality. If the other path is followed, many of these tools are useless and something new must be devised. The differences are not limited to semantics but involve syntax. If we take the non-referential approach by means of temporal operators for tenses, then de re-de dicto distinctions become crucial. Those are usually assumed to rely on syntactic operations, which interact with many other such devices, so that evidence in favor of or against them can be gathered and assessed on syntactic grounds. Similarly, we will see that the two views exploit different syntactic structures for temporal locating phrases such as next May or the Sunday you left.

The purpose of this chapter is to stimulate a critical attitude toward issues of temporal reference in linguistic theory, keeping in mind that temporal reference and tense are not one and the same notion, though they are strongly connected. Temporal reference can be defined as the relation between the time at which an utterance is uttered and the time the utterance is about (for extensive discussion on this point, see Tonhauser 2015), whereas tense is just one of the means available to language to attain temporal reference. Other means are temporal adverbs (or adverbials) and aspectual properties. Hence, according to this perspective, a theory of temporal reference is a sort of metatheory in which the various theories of tense and aspect are located. Recall also that some languages, for instance Mandarin Chinese, do not have tenses, and therefore the way in which temporal reference is attained in them is very different from the way in which it is attained in languages with tenses such as English. Moreover, languages differ considerably in the richness of the morphological system employed in the expression of temporal and aspectual relations. For instance, languages such as Spanish and Italian have a much richer temporal and aspectual morphology than English. These topics cannot be included in the present 
chapter, which is aiming only at a general discussion of temporal reference. Some topics, such as subordination and temporal adverbs, will be considered in greater detail (though not exhaustively), to show how the general system might work, but they are not the focus of the chapter either.

We will proceed as follows. In section 2 we make a cursory review of the basic tenets of tense-logical approaches. These have the interesting property of exemplifying many of the problems non-referential views have to address, despite the fact that they still rely on an ontology of time points, intervals, and the like. The shortcomings of tense-logical theories have been taken to provide support for fully referential views. These will be the topic of section 3, where phenomena such as the syntax of tenses, the sequence of tense (SOT), and temporal locating phrases will be discussed. Special emphasis will be placed on the Reichenbachian and on the neo-Reichenbachian view. In section 4 we turn to the non-referential, tensed view by presenting Ludlow's proposal. To facilitate comparisons, we will focus on the same set of phenomena discussed in section 3, investigating how they can be dealt with in a tensed framework.

\section{Tenses as sentential operators}

Tense-logical approaches to time in natural language (see Prior 1967; Montague 1974) consider tenses as sentential operators, which apply to basic (untensed) sentences to yield other, tensed sentences. Semantically, they shift the evaluation time of a sentence to the past or to the future. In the cases we are going to consider, the evaluation time always coincides with the time of the utterance, symbolized by $u$.

Consider the following examples:

(1) a. John saw Mary.

b. P[see (John, Mary)]

(2) a. John will see Mary.

b. F[see (John, Mary)]

The logical form for (1a) is (1b), where $P$ is the operator for past. Analogously, in the case of a future tense verb (will see), the operator is F. A possible model for this logic is a triple $\mathrm{M}=(\mathrm{T},<, \mathrm{V})$ where $\mathrm{T}$ is a set of moments of time, $<$ is the binary relation earlier than on $\mathrm{T}$, and $\mathrm{V}$ is the interpretation function that assigns a truth value $\mathrm{V}_{\mathrm{t}}(\phi)$ to each propositional formula $\phi$ and to a moment of time $t \in T$. The relevant truth conditions for the operators $\mathrm{P}$ and $\mathrm{F}$ are given in (3a) and (3b) respectively:

(3) a. $V_{M, t}(P \phi)=$ true iff there is $\mathrm{t}^{\prime}, \mathrm{t}^{\prime}<\mathrm{t}$ and $\mathrm{V}_{\mathrm{M}, \mathrm{t}^{\prime}}(\phi)=$ true.

b. $V_{M, t}(F \phi)=$ true iff there is $t^{\prime}, t<t^{\prime}$ and $V_{M, t^{\prime}}(\phi)=$ true.

That is, $\mathrm{P} \phi$ is true at the evaluation time $\mathrm{t}$ with respect to a model $\mathrm{M}$ iff there is a time $t^{\prime}$ that is past with respect to $t$, and $\phi$ is true at $t^{\prime}$ with respect to $M$. Analogously, F $\phi$ is true at the evaluation time $t$ with respect to a model $M$ iff there is time $t^{\prime}$ that is in 
the future with respect to $t$, and $\phi$ is true at $t^{\prime}$ with respect to M. Applying (3) to (1) and (2), we obtain (4):

(4) a. $\mathrm{V}_{\mathrm{M}, \mathrm{t}}\left(\mathrm{P}\left({ }^{\prime} \mathrm{J}\right.\right.$ John see Mary' $\left.)\right)=$ true iff there is $\mathrm{t}^{\prime}, \mathrm{t}^{\prime}<\mathrm{t}$ and $\mathrm{V}_{\mathrm{M}, \mathrm{t}^{\prime}}\left({ }^{\prime} \mathrm{J}\right.$ ohn see Mary' $)=$ true.

b. $\mathrm{V}_{\mathrm{M}, \mathrm{t}}\left(\mathrm{F}\left({ }^{\prime} \mathrm{J} J\right.\right.$ hon see Mary' $\left.)\right)=$ true iff there is $\mathrm{t}^{\prime}, \mathrm{t}<\mathrm{t}^{\prime}$ and $\mathrm{V}_{\mathrm{M}, \mathrm{t}^{\prime}}\left({ }^{\prime} \mathrm{J}\right.$ ohn see Mary') $=$ true.

That is, John saw Mary is true at a time $\mathrm{t}$ iff there is a time $\mathrm{t}^{\prime}$ which precedes the time of the utterance and the untensed proposition 'John see Mary' is true at $\mathrm{t}^{\prime}$. On the other hand, John will see Mary is true when uttered at a time $t$ iff there is a future time $\mathrm{t}^{\prime}$ such that $\mathrm{p}=$ 'John see Mary' is true at $\mathrm{t}^{\prime}$. As can be seen from (3), both F and $\mathrm{P}$ have an existential flavor, in that their truth conditions require the existence of a time at which the proposition they apply to is true. Classical Priorean tense logic also includes the corresponding universal operators $G$ and $H$, where $G \phi$ can be paraphrased as 'in the future it will always be the case that $\phi^{\prime}$ and $\mathrm{H} \phi$ as 'in the past it has always been the case that $\phi^{\prime}$.

Importantly, tense operators can be combined to yield more complex configurations. Such a possibility has been exploited to capture the meaning of compound tenses such as the English pluperfect, which could be seen as the composition of two past operators, PP, and of the future perfect (represented as PF).

The tense operator approach has been criticized from both an empirical and a theoretical point of view. We will consider some of these criticisms, namely those discussed by Enç (1986), and others that arise from observations originally made by Kamp 1968).

If tenses are operators, we expect them to exhibit scope properties analogous to those of other operators and quantified expressions, such as determiner phrases (DPs). Consider (5):

(5) All rich men were poor children.

(Enç 1986, ex. 3)

The meaning of (5) can be paraphrased as in (6):

(6) All rich men (past and present ones) were at a previous time poor children.

The logical forms for (5) are given in (7):

(7) $\quad$ a. $\quad \forall x($ rich-man $(x) \wedge P($ poor-child $(x)))$

b. $\mathrm{P}(\forall \mathrm{x}(\operatorname{rich}-\mathrm{man}(\mathrm{x}) \wedge$ poor-child $(\mathrm{x})))$

The verb were instantiates a past operator P. Furthermore, in (5) the universally quantified DP all rich men appears. Given that operators manifest scope properties, we expect the temporal operator P to interact with the quantified DP, each possibly taking scope on the other. Consider the case where the universal quantifier has wider scope, thus yielding (7a). The corresponding proposition is true iff, for every presently rich man $\mathrm{x}$, there is a past time at which $\mathrm{x}$ is a poor child. This is not the 
meaning of (5) according to our intuitions, because it takes into account only presently rich men. If we let the tense operator take scope over the universal operator, $(7 \mathrm{~b})$ is obtained, a proposition that is true iff there is a past time $t$ such that every man who is rich at $t$ is also a poor child at the same past time. Again, we are far from the meaning of (5) as expressed by (6). Thus both scope possibilities fail to capture (5), and it seems that a standard account of the scope interactions of a tense operator with quantified expressions does not suffice to obtain the correct result (for more recent work about the temporal properties of noun phrases, see Musan 1995).

It has also been observed that tense operators introduced by verbal morphology are not sufficient to account for some interpretive facts. Consider, for example, the following sentence (Enç 1986, ex. 13):

(8) Every fugitive is now in jail.

The operator approach assigns (8) the following meaning:

(9) Every $x$ who is now a fugitive is presently in jail.

Example (8), however, is an assertion about past fugitives who are presently in jail. The correct truth conditions are exemplified by (10):

$$
\forall x((\mathrm{P}(\text { fugitive }(\mathrm{x}))) \wedge \text { in-jail }(\mathrm{x}))
$$

To obtain (10), it must be assumed that the past-tense operator $\mathrm{P}$ is instantiated by the subject DP. Notice in fact that the verbal tense is present and therefore cannot be the verb that instantiates the operator. Moreover, the scope of the operator should not include the predicate and should be restricted to the subject. Generally, however, tense operators are introduced by tense morphemes related to the verbs and have the predicate in their scope. In (8) and similar cases, there is no such past-tense morpheme - that is, there is no morphosyntactic evidence of its presence and no obvious way to constrain the scope of this operator to the DP. In principle, an operator associated with the DP could take scope over the whole sentence. In this case we would obtain (11):

(11) $\forall x(P($ fugitive $(x) \wedge$ in-jail $(x)))$

Example (11) is true iff everyone who was a fugitive at a past time was in jail at that same time. Again, such a reading is not the correct one. Therefore the hypothesis according to which DPs introduce tense operators does not make the correct predictions. The scope properties of such operators in fact are anomalous and should be constrained by means of ad hoc conditions. Consider also that, if it were correct to hypothesize the presence of an operator taking scope over the DP, we should also investigate the scope relations between two DPs, each bearing its own temporal interpretation (and, consequently, its own tense operator). In particular, when a DP is c-commanded by another one, we would expect the temporal interpretation 
of the former to depend on the temporal interpretation of the latter. Consider the example in (12) (modeled on Enç 1986, ex. 8):

\section{Every student will have met a president.}

A possible reading of (12), which is the one relevant to our discussion, is as follows: let us hypothesize a scenario where every present student either met, or is meeting, or will meet at a future time the president in charge at that moment. Sentence (12) is true at the time of utterance if there is a later time at which Every student met a president is true. In this scenario, the DP every student is evaluated at the present time, whereas a president can be evaluated at a past, present, or future time. That is, the times relevant for the two DPs must be kept separate, so that the temporal interpretation of the DP a president does not depend on the interpretation of the DP every student, even if a president is in the scope of the latter. As a consequence, the expectation that tense operators introduced by DPs exhibit the scope properties of ordinary quantified expressions is not met.

To summarize, tense operators introduced by DPs do not take scope over the main predicate, as shown by (10), and they do not interact with each other, as shown by our discussion of (12). If we still want to maintain the hypothesis that a DP can be associated with a tense operator, we should constrain such a tense operator to take only very local scope, because it seems to have only the DP itself in its scope. As we said in the preceding discussion, this move is possible but requires a rather ad hoc hypothesis.

Another argument against the use of tense operators comes from the analysis of the interactions between tenses in complex sentences. Consider (13), which is owed to Kamp (1968):

(13) a. A child was born who would be king.

b. A child was born who will be king.

$$
\mathrm{P}(\exists \mathrm{x}(\operatorname{child}(\mathrm{x}) \wedge \operatorname{born}(\mathrm{x}) \wedge \mathrm{F}(\operatorname{king}(\mathrm{x}))))
$$

The sentences in (13a) and (13b) differ only in the use of two different future forms in the relative clause, namely the auxiliaries would and will. The logical form in (14) represents the meaning of (13a). The future tense operator, introduced by the verb of the relative clause, is in the scope of the tense operator of the main verb. Formula (14) is then true iff there is a past time $t$ at which a child was born and there is a time, future with respect to $t$, when it is true that the child is king. Thus (14) correctly captures the meaning of (13a). On the other hand, it is not so easy to account for the meaning of $(13 \mathrm{~b})$, in which the simple future, will, appears in the relative clause. Formula (14) does not work, for (13b) requires the time at which the child is said to be king to be in the future with respect to the utterance now, something that is not made available by (14). There is an alternative option, namely that the future operator takes scope over the past operator of the matrix clause, yielding (15):

$$
\mathrm{FP}(\exists \mathrm{x}(\operatorname{child}(\mathrm{x}) \wedge \operatorname{born}(\mathrm{x}) \wedge \operatorname{king}(\mathrm{x})))
$$


Formula (15), however, is not a correct representation of (13b) either, since it requires a future time $\mathrm{t}$ and a time $\mathrm{t}^{\prime}, \mathrm{t}^{\prime}<\mathrm{t}$, such that born $(\mathrm{x})$ and $\operatorname{king}(\mathrm{x})$ are both true at $\mathrm{t}^{\prime}$. What is needed for $(13 b)$ is the possibility for the two tenses to be independently evaluated with respect to the time of utterance. Tense logic, however, cannot represent the two operators as being independent from each other.

The examples in (13) raise a problem very similar to those discussed by Enç. One major inadequacy of the tense operator approach seems to be that the interactions among the temporal properties of the constituents of a sentence are not the ones expected for tense operators. In other words, an operator-based representation is insufficient to account for the temporal interpretation of the sentences considered above.

Another problem with the tense-logical approach is the possibility of compounding the basic operators $\mathrm{F}$ and $\mathrm{P}$ to make them yield more complex ones. On the one hand, languages like English have tenses that seem to be naturally analyzable by means of such a property. For instance, the pluperfect and the future perfect could correspond to PP and FP, respectively. On the other hand, there are compound tenses that resist a similar treatment. For example, the present perfect cannot be straightforwardly distinguished from the simple past by virtue of operator compositions.

Another problem is that nothing prevents an unlimited composition of tense operators. Any sequence is a priori possible - for example FPF, PPP, FPFP - even if none of its elements corresponds to an observable tense in any language. The composition of operators could be constrained by means of ad hoc conditions, for instance by explicitly disallowing combinations of more than two operators. This move, however, weakens the explanatory adequacy of the temporal logic approach.

Finally, tense-logical approaches have notorious problems with the treatment of temporal anaphora. Consider (16) and (17):

(16) John left the room. He was furious.

(17) John said that Mary was pregnant.

In (16) the second sentence is understood as holding at the same time as the first. Example (17), on the other hand, can mean either that Mary's pregnancy holds at the time of John's utterance or that the pregnancy is at an earlier time. Thus, both in (16) and (17), there seems to be a dependency of the time of the second clause (he was furious and Mary was pregnant) on the time of another clause.

The operator approach cannot easily account for the facts in (16) and (17). Anaphoric phenomena, in fact, seem to require the availability of entities, such as times and events (but also ordinary individuals who refer to spatial objects), which can be introduced in the discourse context, stored, and accessed for later reference. No natural notion of context is possible with tense logic, unless major changes are proposed, undermining the spirit of these logical systems (for a discussion, see Kamp and Reyle 1993). Furthermore, although tense logic does make use of temporal entities, it does so at the level of the metalanguage, in the truth conditions for operators. Hence there are no terms referring to temporal entities in the object language (see the logical forms given above). This way of encoding the temporal 
dimension was motivated by considerations about verbal tenses, since their intrinsic relational meaning can be captured by means of truth conditions such as those in (3), repeated here for simplicity:

(18) a. $V_{M, t}(P \phi)=$ true iff there is $t^{\prime}, t^{\prime}<t$ and $V_{M, t^{\prime}}(\phi)=$ true.

b. $V_{M, t}(F \phi)=$ true iff there is $t^{\prime}, t<t^{\prime}$ and $V_{M, t^{\prime}}(\phi)=$ true.

Verbal tense, however, is not the only manifestation of time in natural languages, and there are cases in which direct reference to temporal entities seems to be needed. Apparently this is the case of temporal anaphora, as has been seen, and presumably also that of temporal adverbials such as at four, yesterday, and so on. There are, therefore, many cases where direct reference to times appears to be necessary.

\section{Temporal entities}

In the previous section we have shown that (i) the temporal properties of sentences cannot be easily accounted for by means of the scopal dependencies among temporal operators; (ii) the compositional character of temporal operators does not provide an upper limit to the number of temporal operators that can be combined to yield tenses, failing therefore to explain the limited variety of tenses found in natural languages; and (iii) tense logic does not provide an account of temporal anaphora and of certain expressions that seem to require the availability of terms that refer to times. All these considerations seem to favor a referential approach - that is, an approach that allows temporal reference directly in the object language, thus permitting an analysis of tenses, and temporal adverbials as referring (or involving reference) to temporal entities. Before turning to more details about the referential approach, let us emphasize that the basic opposition between the temporal logic approach and the so-called referential one is linguistic, not ontological-metaphysical. That is, both admit the reality of times (points, intervals, or whatever) with their usual properties (e.g., precedence). The difference is in logical language: in one case, terms referring to those entities are exploited; in the other, reference to times is relegated to the metalanguage. As we will see, there is a more radical option, which expunges times from all levels of the logical language, prohibiting reference to it tout court. Before we continue, let us point out that my considerations will often be cast in a truth-theoretic semantic framework inspired by the work of Higginbotham $(1991 ; 2009)$ and Larson and Segal (1995). There is obviously no space here to discuss their approach in any detail, but the interested reader can consult these three works. For present purposes, it is enough to say that (a) the theory uses a ternary relation Val between an entity $\mathrm{x}$, a linguistic object $\Sigma$, and an assignment sequence $\operatorname{Val}(\mathrm{x}, \Sigma, \sigma)$ that signals that $\mathrm{x}$ is a value for $\Sigma$ under assignment $\sigma$, and (b) this will be the basic building block for the chapter's semantic work.

We start by considering how tenses can be accounted for in a referential approach. The simpler possibility is to have them introduce relations between temporal entities; for example, the past tense states that the time of the event precedes the time of the speech or, alternatively, that the event talked about in the clause precedes the event of the speech or utterance. Syntactically, tense morphemes are of the 
category T, project a constituent tense phrase (TP), and take verb phrase (VP) complements. Hypothesizing that the last two are predicates of events, we could write the following axioms for $\mathrm{T}$ :
a. Val $(\mathrm{e}$, Past, $\sigma)$ iff $\mathrm{e}<\mathrm{u}$
b. $\operatorname{Val}(\mathrm{e}$, Pres, $\sigma)$ iff $\mathrm{e}^{\circ} \mathrm{u}$
c. Val(e, Fut, $\sigma)$ iff e $>u$

They say that, for a given assignment sequence $\sigma$, the value of a tense morpheme is event e iff such an event precedes the utterance (past tense), overlaps with the utterance (present tense), or follows the utterance (future tense). The event is provided by the VP and the combination of the tense with that phrase is ruled by the following axiom:

$$
\operatorname{Val}(\mathrm{e},[\mathrm{TP} T \mathrm{VP}], \sigma) \text { iff } \operatorname{Val}(\mathrm{e}, \mathrm{VP}, \sigma) \text { and } \operatorname{Val}(\mathrm{e}, \mathrm{T}, \sigma)
$$

This axiom says that event $\mathrm{e}$ is a value of [TP $\mathrm{T}$ [VP ran]] iff $\mathrm{e}$ is the value of the VP and of the node T. The axiom for the relevant tense, (19b), eventually constraints the event to precede the utterance.

It has been observed that this simple picture is not easy to extend to compound tenses. To this end, it might be worth considering the work done in the Reichenbachian tradition, starting from Reichenbach (1947). In this perspective, the correct temporal interpretation of tenses requires three temporal entities, not just two; it adds the so-called reference time/event, $r$, to the already seen event (time) and utterance (time). With this addition, tenses become devices ordering the three temporal entities. For example, the meaning of the present tense could be represented as $\mathrm{u}^{\circ} \mathrm{r}^{\circ} \mathrm{e}$, which states that the event (time) overlaps the reference time/event, and the latter overlaps the utterance.

The Reichenbachian model has been adopted and revised by several linguists (among others, Comrie 1976; 1985; Vikner 1985; Declerck 1986; Hornstein 1990; Scorretti 1991; Giorgi and Pianesi 1997). As already suggested by Reichenbach and then further discussed by Comrie (1985) and Hornstein (1990), for both empirical and theoretical reasons it has been proposed that the relation among the three points be split into two distinct relations, one between $r$ and $u$, and the other between e and $r$. The result is a system in which a direct relationship between e and $\mathrm{u}$ is never realized but is always mediated by $\mathrm{r}$. The possible relations are the following:

(21) Type 1 relation Type 2 relation

$$
\begin{array}{ll}
u>r \text { future } & e>r \text { perfect } \\
r>u \text { past } & r>e \text { prospective } \\
u^{\circ} r \text { present } & e^{\circ} r \text { neutral }
\end{array}
$$

As a consequence, the various tenses are the result of the composition of a relation of type 1 with a relation of type 2 . For instance, according to this picture, the representation of the present tense is the result of the combination of $u^{\circ} r$ with $e^{\circ} r$, which yields $u^{\circ} r^{\circ}$ e. The representation of the present perfect is the result of the 
combination of $u^{\circ} r$ with e $>r$, which yields e $>r^{\circ} u$. From the point of view of the final representation, this proposal exhibits an important empirical difference with respect to the original Reichenbachian one. The point, often discussed in the literature (see Comrie 1985 and Hornstein 1990), concerns the future perfect. Such a tense results from the combination of $u>r$ and $e>r$. Comrie points out that in English (and in Italian as well), a sentence such as (22) is ambiguous in three ways:

(22) John will have finished his manuscript by tomorrow.

The exact temporal relation between the finishing of the manuscript and the utterance is unknown. It could be that, when the sentence is uttered, John has already finished the manuscript; or that he is finishing it exactly at that moment; or that he will finish after the utterance and before tomorrow. This ambiguity is nicely captured by the following combination of type 1 and type 2 relations:

(23)

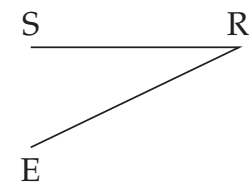

As pointed out by Comrie and then by Hornstein, the revised Reichenbachian framework presents several other advantages over the original one. According to the latter, in fact, we would in principle expect the existence of languages where, for each possible position of e, there is a morphologically different realization. In other words, Reichenbach predicts the existence of languages in which the meanings corresponding to $\mathrm{u}>\mathrm{e}>\mathrm{r}, \mathrm{u}^{\circ} \mathrm{e}>\mathrm{r}, \mathrm{e}>\mathrm{u}>\mathrm{r}$ are expressed by means of different morphological tenses. Comrie points out that this does not seem to be the case.

Also, we have a way to account naturally and elegantly for the limited number of morphologized tenses, a problem that plagued the tense operator approach of the previous section. The system is based on three primitive objects, plus binary relations. In consequence, the possibilities of combining the various forms are very limited. Finally, as pointed out by Hornstein (1990), such a system can be easily acquired, satisfying therefore an important requirement for any theory of tense. The inventory of resulting tenses is the following (the list is basically the one in Hornstein 1990, 117, with the addition of the distant future):

(24) Present:

Past:

Future:

Present perfect:

Future perfect:

Past perfect:

Future in past:

Proximate future:

Distant future:

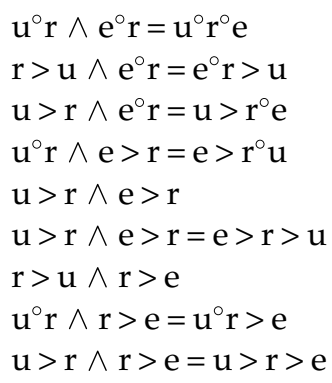




\subsection{The syntax of tense}

Given the revised Reichenbachian framework reviewed in the previous section, the possibility arises that the two types of relations between temporal entities correspond to two tense heads, T1 and T2, which realize type 1 and type 2 relations respectively. Such a distinction can be justified by showing that the morphemes that realize $\mathrm{T} 1$ and $\mathrm{T} 2$ have different contents in terms of features and different morphosyntactic behaviors and that this predicts the legitimate combination of these two categories, and hence of available tenses.

This possibility has been pursued by Giorgi and Pianesi (1997), who proposed that tenses are doubly represented in clausal structure as a result of the existence of two projections, T1 and T2, where T1 is higher than T2. For example, a compound tense such as the Italian or the English past perfect (had eaten) or future perfect (will have eaten) would correspond at least to the following structure:

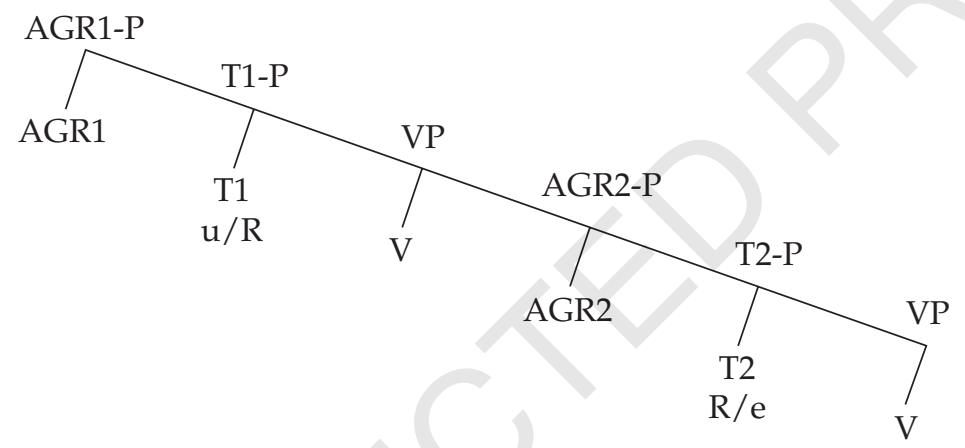

Here T1 introduces the relation between the utterance and the reference point, whereas T2 takes care of relating the latter to the event. The lower VP is projected by the verb, whereas the higher one is projected by the auxiliary. AGR1 represents the set of phi-features, for instance person and number, that are shared with the subject - that is, with (Spec, AGR1"). AGR2 can be specified for gender and number features, as in Italian. As can be seen, Giorgi and Pianesi (1997) assign a biclausal structure to complex tenses and treat the contribution of T1 and T2 in essentially the same manner. A past tense, be it expressed by T1 or by T2, places the (entity corresponding to the) variable instantiated by the complement of the tense node before another entity, the reference time/utterance event. The lower clause is responsible for relating the event (time) and the reference time/event. The upper clause handles the variable instantiated by $\mathrm{T} 2$, relating it to the utterance. This can be captured as follows:

(26) a. $\operatorname{Val}(<\mathrm{x}, \mathrm{y}>, \mathrm{T} 2, \sigma)$ iff $\operatorname{rel}(\mathrm{x}, \mathrm{y})$ where rel is $>,<$, or $^{\circ}$ depending on whether $\mathrm{T} 2$ is past, future, or present.

b. $\operatorname{Val}(\mathrm{y},[$ T2P T2 VP], $\sigma)$ iff $\operatorname{Val}(<\mathrm{x}, \mathrm{y}>, \mathrm{T} 2, \sigma)$ and $\operatorname{Val}(\mathrm{x}, \mathrm{VP}, \sigma)$.

c. $\operatorname{Val}(\mathrm{y},[\mathrm{vP} \operatorname{Aux} \mathrm{T} 2 \mathrm{P}], \sigma)$ iff $\operatorname{Val}(\mathrm{y}, \mathrm{T} 2 \mathrm{P}, \sigma)$.

d. $\operatorname{Val}(\mathrm{z}, \mathrm{T} 1, \sigma)$ iff $\operatorname{rel}(\mathrm{z}, \mathrm{u})$, where rel is $>,<$, or $^{\circ}$ depending on whether T1 is past, future, or present.

e. $\operatorname{Val}(\mathrm{z},[\mathrm{T} 1 \mathrm{P} T 1 \mathrm{VP}], \sigma)$ iff $\operatorname{Val}(\mathrm{z}, \mathrm{T} 1, \sigma)$ and $\operatorname{Val}(\mathrm{z}, \mathrm{VP}, \sigma)$. 
We have avoided using the variables e and $r$ in (26) in order to stress the strong symmetry between the two tenses. Thus, when $\mathrm{T} 2$ is realized through a past-tense morpheme, (26a) and (26b) jointly ensure that the value of T2P is an entity (the reference event) that happens before the entity introduced by the VP (the event). Moreover, if T1 is a future morpheme, then the value of T1P is the entity realized by the VP, the latter turning out to be the same as the value of the embedded T2P. As before, the indexical nature of T1 tenses is handled directly by axiom (26d).

Those axioms provide a simple treatment of the second variable (the reference time/ event). A more detailed account should accommodate the fact that this variable can draw its reference from the context or be bound by a quantificational expression, as in:

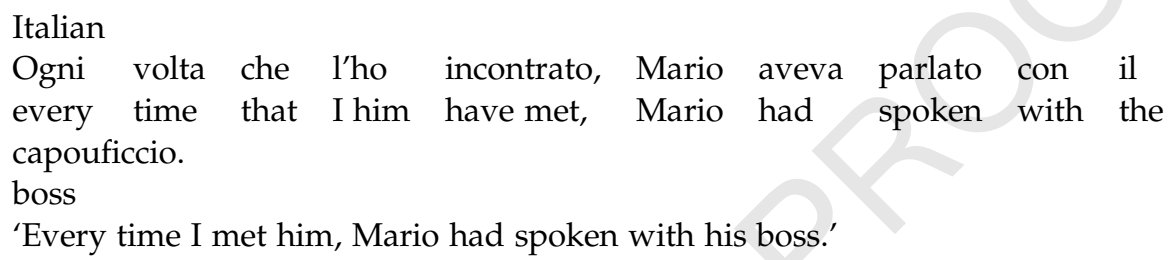

The variable corresponding to $\mathrm{r}$ can be either a temporal entity - a time point or interval - or an eventuality, depending on the framework adopted. The second possibility enables us to introduce considerations a là Parsons (1990) about consequent states. The first alternative can be used to accommodate insights that rely on the notion of an extended now, as in Dowty (1979). Finally, notice that, on this approach, the three Reichenbachian points lose any privileged status and become a side effect of the interplay between the syntactic and semantic properties of tense morphemes and the structures they enter into.

Other authors have elaborated on the idea of a biclausal (and even multiclausal) structure for tenses. Thus Julien (2001) proposes that simple sentences involve both a TP-past and a TP-future, the former taking the second as its complement, and the latter the VP. Both T-past and T-future can have \pm values:

$$
\text { [TP-past T-past } \left.{ }_{[ \pm \text {past] }}\left[\text { TP-future T-future }{ }_{[ \pm \text {future] }}[\mathrm{VP}]\right]\right]
$$

When T-past has [+past] and T-future has [-future], the result is a simple past. Vice versa, if T-past is [-past] and T-future is [+future], we have a simple future. The present tense results from a configuration where both features have the value -, and, as in Giorgi and Pianesi, the relevant interpretation is the result of a default process. Finally, Julien admits the possibility that both features have a + value, exemplifying this possibility with the English future in the past, would. This structure is extended to complex tenses by duplicating the structure below the auxiliary in (28). In what follows a brief overview of some important proposals will be sketched, most notably the ones in Cinque (1999) and Stowell (1996; 2007).

\subsubsection{The cartographic approach}

The basic tenet of the cartographic proposal is that syntactic structure is projected according to a universal pattern, starting from the morphosyntactic features. To each morphosyntactic feature corresponds a syntactic projection (see Cinque and 
Rizzi 2008). Hence the basic minimalist structure C-T-v-V becomes a shorthand for a much more articulated structure, organized around these projections in layers, namely the V-layer with all its projections, the T-layer, and the C-layer. Categories, tense and aspect included, are usually treated as bundles of binary features. Accordingly, temporal projections in the T-layer and aspectual projections in the V-layer are projected by their corresponding binary features. The temporal categories hypothesized by Cinque (1999), following Vikner (1985), are three and are projected by \pm past, \pm future, and \pm anterior; their combinations give rise to the possible tenses in the various languages. It must be kept in mind, however, that the analysis of tense, aspect, and SOT is not the main goal of the cartographic approach, which aims primarily at a general theory of phrase structure. For this reason, such analysis cannot be considered a full-fledged alternative to any theoretical proposal concerning temporal reference and SOT. In particular, we can observe that, while it might be reasonable to consider aspectual properties as projections of binary features, it is certainly more difficult to consider tenses in the same way, especially on the basis of what is known about the properties of SOT, which will be illustrated in section 3.2 below. Notice however, that, in the light of the findings of the cartographic approach, the low tense projection in Giorgi and Pianesi's (1997) framework - that is T2 - can be considered as expressing an aspectual value more than a purely temporal one. In particular in Italian, as in many other languages, it expresses a perfective value. Cinque (1999, ex. 96) hypothesizes the existence of many aspectual projections above the verbal ones, in the following hierarchical order: perfect $>$ retrospective $>$ durative $>$ progressive $>$ prospective $>$ celerative $>$ completive $>$ repetitive $>$ iterative. Actually in many languages the only aspects clearly marked by means of verbal morphology are the perfect - or, to use a better word, perfective and the progressive ones. The perfect aspect is the highest in Cinque's hierarchy; therefore, if one wants to draw a parallelism between Giorgi and Pianesi (1997) and cartography, one could say that T2 may be considered as a succinct notation for the aspectual layer, represented in Italian (as well as in many other languages) by perfectivity.

\subsubsection{Stowell's approach}

In 1996 Stowell proposed a syntactic view of tenses, developing some ideas originally discussed in Zagona (1990); then he took his ideas further in 2007. In her work, Zagona argued that tenses have the syntax of two-place predicates, where the argument in the specifier position of tense is constituted by the time of utterance and the internal argument is constituted by eventuality associated with the verbal projection. In the same vein, Stowell argues that tenses can be viewed as two-place predicates, as they take two time-denoting expressions as their arguments. The internal argument, similarly to what Zagona hypothesized, contains the verbal projections and the event time, whereas the external argument denotes a time that functions as reference time. The most important components in Stowell's proposal are a theory of control and a theory of past polarity that determine the temporal location of the event. Control theory is used to derive the difference between main and complement clauses with respect to the denotation of $R$ (reference), whereas past polarity accounts for the interpretation of the English past tense in clauses embedded under past tenses and of the present tense in relative clauses that depend on a past tense. 
Past polarity is built by analogy to the theory of negative polarity. In the next section we ill consider SOT and will further discuss Stowell's proposal. For interesting developments of similar ideas, see Demirdache and Uribe-Etxebarria (2007).

\subsection{Sequence of tense}

Up until now our discussion of the referential theory has been limited to tenses in matrix clauses. In complement clauses, especially when predicates of propositional attitudes are involved, tenses behave in peculiar ways, giving rise, in languages such as English, to so-called SOT phenomena. An important tenet of SOT is that anchoring of a subordinate verb to a superordinate one, and eventually to the utterance time, is obligatory, as discussed in Enç (1987). Thus the utterance of (29) can be understood as reporting either a present tense utterance of John's - for example Mary is ill - or a past-tense utterance - for example Mary was ill:

(29) John said/believed that Mary was ill.

Within the approach under discussion here, the backward-shifted reading can be captured by assigning (29) the following truth-conditions:

(30) $\exists e($ saying $(e) \wedge \operatorname{Agent}(e$, John $) \wedge$ Theme $(e, \psi) \wedge e<u)$

Here $\psi$ is the interpreted logical form (ILF) for the subordinate clause with the following truth conditions:

(31) $\exists \mathrm{e}^{\prime}\left(\right.$ ill $(\mathrm{e}) \wedge$ Theme $\left(\mathrm{e}^{\prime}\right.$, Mary $\left.) \wedge \mathrm{e}^{\prime}<\mathrm{e}\right)$

Once the two are put together, we have:

(32) $\exists e\left(\right.$ saying $(e) \wedge$ Agent $(e$, John $) \wedge$ Theme $\left(e,[] \exists e^{\prime}\left(\right.\right.$ ill $(\mathrm{e}) \wedge$ Theme $\left(\mathrm{e}^{\prime}\right.$, Mary $\left.\left.) \wedge \mathrm{e}^{\prime}<\mathrm{e}\right)[]\right)$ $\wedge \mathrm{e}<\mathrm{u})$

What is important here is that the truth conditions for the subordinate clause explicitly mention the episode of saying, letting the tense relate it to the embedded eventuality (the illness; see Higginbotham 1995 and 2009 for more on this topic). This establishes a parallel between the role played by the matrix eventuality - the subject's attitude episode - in the subordinate clause and the role played by the utterance in the matrix. In both cases, the tokening of an expression by an agent is used as a temporal coordinate from which the tense's contribution is computed. This parallel can be further pursued, as in Giorgi and Pianesi (2001a; 2001b), in order to account for the lack of mere indexical readings of tenses in subordinate clauses. Thus (33) cannot be used to mean that John said something concerning the very time at which (33) is uttered - that is, the speech time; nor can (29) be used to report a dictum concerning events located in the past only with respect to the utterer for example something that is future-oriented with respect to John.

(33) Last week John said that Mary is pregnant. 
It seems therefore that, whenever there is a tokening of a linguistic expression (as in matrix clauses) or a report about such a tokening (as in subordinate contexts), the temporal coordinates of the tokener must be explicitly given and connected to the event the expression is about. In other words, the ILF that represents the object of a propositional attitude must explicitly represent the attitude episode itself and use it to locate the event that is talked about.

\section{(34) Conditions on propositional attitudes}

a. A clause is the object of an attitude by a subject iff the ILF of that clause contains the subject's temporal egocentric coordinate.

b. The primary role of tense is to locate the event with respect to such a coordinate.

c. The temporal coordinate of the subject is the attitude's episode itself.

Principle (34) correctly predicts that tenses in subordinate contexts cannot be mere indexicals, for that would amount to linking the event to the utterance, hence to the speaker's coordinate, violating (34). Moreover, the principle dissolves the notion of temporal anchoring (see Enç 1987) into the more general requirement that the contents of propositional attitude explicitly represent the attitude episode itself. Finally, the principle suggests that the assignment sequences that are used to compute the interpreted logical forms of clauses subordinated to verbs of propositional attitude had better be relativized to subjects. By this we mean that, on the backward-shifted reading, was in (29) is evaluated as if it were the subject's (John's) was, hence relating the state of illness to his coordinate - his saying or his belief (or thought) - rather than to the speaker's - the utterance. We do not discuss here how this idea can be implemented (for this the reader should consult Giorgi and Pianesi 2001b). Suffice it to say that the availability of subject-oriented assignment sequences provides for the desired truth conditions (30) and (32).

Turning to the simultaneous reading of (29), it can be given the following truth conditions:

$$
\begin{aligned}
& \exists e\left(\text { saying }(e) \wedge \text { Agent }(e, \text { John }) \wedge \text { Theme }\left(e,[] \exists e^{\prime}\left(\text { ill }(e) \wedge \text { Theme }\left(e^{\prime}, \text { Mary }\right) \wedge e^{\prime \circ} e\right)[]\right) \wedge\right. \\
& e<u)
\end{aligned}
$$

These truth conditions are consistent with the discussion above and with (34): the ILF of the subordinate clause explicitly represents the subject's temporal coordinate, and the tense relates the subject's temporal coordinate to the event. As before, this result is obtained by computing the ILF of the subordinate clause by means of a subject-oriented assignment. With respect to the other reading, however, the wellknown problem arises of how to accommodate the fact that an embedded past tense, like that of (29), behaves as if it were a present tense. Roughly speaking, the explanations provided in the literature are of two kinds. According to one view, the embedded past tense is only "apparent" in (29); one might in fact argue that it is present during part of the derivation, but then disappears at Logical Form (LF), as a result of some deletion that obtains in past-under-past contexts. Another view maintains that the past-tense morpheme was not present during the derivation and got inserted only as a by-product of spell-out. Both views share the idea that 
the LF representation for (29) can have a $\varnothing$ tense morpheme (or no tense morpheme at all), which interpretively yields simultaneity, for example through some default mechanism. This approach was quite popular some times ago. More recently it has been exploited by Ogihara (1995), though it has lost some of its appeal, because it requires postulating mechanisms (deletion or insertion) that are not so readily available any longer.

Another tradition has it that the past tense is morphologically present but can be interpretively transparent, be that because the embedded past tense enters some kind of agreement process with the matrix tense, because it acts as a scope marker for it, or through some similar mechanism. A proposal in this direction is that advanced by Abusch (1997). She hypothesizes that superordinate tenses can place constraints on subordinate ones and that, vice versa, subordinate tenses inherit restrictions from superordinate ones. Thus she speaks of a local relation, together with transmitted ones. In the case of a past-under-past sentence, the constraint is that at least one of these relations taken together (the local and the transmitted ones) is temporal precedence. More precisely, she assumes the following:

(36) a. Tenses come with a relational variable relating their index to the local evaluation time.

b. Verbs such as believe transmit the relation associated with their tenses to their clausal complements, through a feature-passing mechanism. Hence embedded tenses have access to all the relations associated with higher tenses.

c. The semantics of tense is a constraint on the set of all available relations. For the past, the constraint is that at least one of them be precedence.

Given this, the simultaneous reading of (29) follows: (i) the constraint on the subordinate past tense is satisfied by the inherited precedence relation, and (ii) this makes it possible to understand the embedded event as simultaneous with the act of saying.

Another possibility is the one pursued by Stowell $(1996 ; 2007)$, who draws a parallel between tenses in subordinate contexts and polarity items. In his view, the past tense is a past-polarity item, which means that, if the past tense is within the scope of another past tense, it behaves like anybody within the scope of negation; nether contributes anything to the interpretation, so that it becomes possible to understand the illness in (29) as simultaneous with the saying. It should be noticed that the actual implementation of both proposals is somewhat underspecified. Abusch's theory of transmitted relation relies on a feature-passing mechanism that is not easy to accommodate within current generative grammar frameworks, such as the one offered by Schlenker's (2003) recent proposal of agreement between semantic indices. Stowell's view, on the other hand, might be said to suffer the same shortcomings as any treatment of polarity, namely that the underlying syntactic mechanisms might be rather stipulative, at least until a specific implementation in a syntactic framework is explicitly worked out.

\subsection{The double-access reading}

Together with some syntactic facts discussed in Giorgi and Pianesi (2000), principle (34) provides an account of double-access sentences (DAR) - for example (33). 
As first observed by Smith (1978), a sentence like the one in (33) has the peculiarity that the pregnancy state referred to in the subordinate clause is simultaneous both to the saying and to the utterance. This doesn't mean that, by using (33), a speaker commits herself to the truth of the complement - that is, to the existence of a state of pregnancy that holds of Mary at the time when the John speaks. Nor is there any commitment to the truth of the complement clause at Mary's - the subject's - time. Indeed the speaker can continue her speech by uttering:

(37) Actually, he was wrong. Mary has just been overeating for the last three months.

Scholars such as Abusch (1997), Schlenker (2003) and Ogihara (1995) have argued in favor of a de re analysis of tenses in these cases, hypothesizing that the embedded present tense gets scoped out in (33) and that both the tense and its trace contribute to the interpretation. Scoping out is obligatory in present-under-past contexts (a) because the constraint on local and inherited relations for the present tense is that none of them be temporal precedence (Abusch 1997), or (b) because the present tense is an anti-past-polarity item (Stowell 1996; 2007).

Once scoped out, the behavior of the present tense is analyzed within a framework built according to Lewis' (1979) suggestions, as further elaborated upon by Cresswell and Von Stechow (1982). On this view, for a subject $X$ to have a de re belief about an object $\mathrm{Y}$ is for $\mathrm{X}$ to ascribe to $\mathrm{Y}$ a certain property $\mathrm{Z}$. Property ascription relies in turn on the subject $X$ 's being suitably connected to object $X$ by means of an appropriate acquaintance relation, which makes the object (epistemically) available to the subject. Omitting details (which can be found in the works cited), the analysis of a DAR sentence such as (33) requires that

(38) a. the present tense be scoped out of the embedded clause;

b. the embedded clause be interpreted as a property of times;

c. a suitable acquaintance relation be found relating the de re (scoped-out) interpreted time or state to the attitude's subject.

In Abusch's account, the first point follows from the already mentioned theory of transmitted relations in intensional contexts: the constraint on the local and the transmitted relations of a present tense is in fact that none of them be temporal precedence. Thus, in a present-under-past sentence, the tense must be scoped out. Finally, Abusch argues that a suitable acquaintance relation for (33) is one that picks out the maximal interval at which Mary has a big belly (the hypothesis is that the speaker is interested in explaining Mary's symptoms), and one that, for independent reasons, picks up an interval that in the actual world overlaps with both the time of the saying and the utterance time.

As should be clear, the offered account of the DAR relies on hypotheses involving both the syntax and the semantics. Concerning the former, it is necessary that the de re tense be scoped out of the embedded clause at LF, hence that a position be made available for it to land in. At the same time, the trigger for such a movement, though spelled out in terms of the constraints on local and transmitted relations, is essentially syntactic: temporal relations are accumulated down the syntactic trees through a mechanism of feature passing, which is typically syntactic (this obviously 
holds in general of Abusch's proposal, hence also of the discussed account of the simultaneous reading of (29)). It is not clear whether and how the syntactic theory can bear the burden of these two requirements. Invisible movement has, however, come under the scrutiny of syntacticians, who question the availability itself of the operation. Concerning the feature-passing mechanism, it is not something that current theories of generative grammar seem able to accommodate. So the basic problem of how temporal dependencies should be handled remains open.

On the semantic side, the de re account has a number of empirical and conceptual shortcomings. Given the constraint on the acquaintance relation, it can explain why an utterance of (33) is odd if Mary's symptoms do not persist at the time of the speech. However, the de re account has difficulties in explaining why the same utterance is odd if the symptoms persist but the situation has changed in relevant respects. Suppose, for instance, that Mary was indeed pregnant when John said what he did, that she delivered just a few days before the report, and that, as often happen in these cases, she still has a big belly. If this is the situation, the DAR report is odd, and the oddness seems to have to do more with the speaker's knowledge or beliefs - that is, with her propositional attitudes - than with John's. Interestingly, the converse also holds. If Mary was not pregnant at the time of John's saying (John was wrong), is now pregnant, and, for whatever reasons, has a big belly all the time, then again (33) is odd. As before, what matters is that, if the speaker knows that the situation has changed, she isn't in a position to use a DAR sentence. These facts are not easily captured by the de re accounts just reviewed.

Finally, on the conceptual side, de re accounts of DAR sentences place a heavy epistemological burden on the speaker's shoulders: she must have quite detailed intuitions about the subject's original situation (mental state, one could say). On the other hand, it seems that one can use a DAR sentence without having any information as to what moved John into saying what he did (the big belly?). Short of saying that the speaker can postulate non-specific acquaintance relations, it is not clear how the vast majority of uses of DAR sentences can be accounted for. But non-specific acquaintance relations don't seem to be what Lewis had in mind when he introduced acquaintance relations; he seemed to mean that they should be of a very specific type.

A different approach to DAR sentences - one that tries to address those concerns was proposed by Giorgi and Pianesi (2001b) and Giorgi (2010). They explicitly attempt to link the temporal interpretation with syntactic facts, while at the same time capitalizing on the idea that, by using a DAR sentence, the speaker expresses an attitude of her own. On the syntactic side, the basic observations concern the fact that, in Italian, DAR contexts typically have the indicative mood and reject complementizer deletion (CD):

(39) Italian

Gianni ha detto (che) tu eri arrabbiato.

Gianni has said (that) you were(IND) angry

'Gianni said that you were angry.'

(40) Italian

Gianni credeva/temeva (che) tu fossi arrabbiato.

Gianni believed (IMPF)/feared(IMPF) that you were(SUBJ) angry

'Gianni believed that you were angry.' 
(41) Gianni ha detto che Maria è incinta.

Gianni has said that Maria is pregnant.

'Gianni said that Maria is pregnant.'

(42) Italian

*Gianni temeva che Maria sia/è incinta.

Gianni feared(IMPF) that Maria is(SUBJ)/is(SUBJ) pregnant

'Gianni feared that Maria is(SUBJ)/is(IND) pregnant.'

On the other hand, contexts that allow $\mathrm{CD}$, such as those induced by verbs like credere ('believe') or temere ('fear'), do not allow the DAR. Thus some connection seems to be at stake between CD and DAR. Giorgi and Pianesi (1997) and Giorgi (2010) capitalize on this observation and argue that the leftmost position in the complementizer layer hosts the speaker's coordinates, which must be available in the syntax for the DAR. The hypothesis is that DAR obtains only if the complementizer $C$ is projected (regardless of the specific tense chosen). To explain this relationship, Giorgi and Pianesi hypothesize that $C$ is endowed with temporal features ( $\tau$-features) that enter a relation with those of the embedded $T$, by either movement or matching. As a result, when the ILF for the embedded clause of (33) is computed and the interpretive contribution of tenses is spelled out, the same eventive variable is present in $\mathrm{C}$ and in $\mathrm{T}$ :

(43) a. $\left[\ldots\left[\mathrm{v}\right.\right.$ said $\left.\left.\left[\mathrm{CP}_{\mathrm{P}}[\tau-\mathrm{C}[\mathrm{xP} \ldots \tau-\mathrm{T} \ldots]]\right]\right]\right]$

b. $\left[\ldots\left[\mathrm{C},<e, x 0_{>} \ldots\left[\mathrm{T},<e, x 0_{>} \ldots\right]\right]\right]$

The C-node is invariably associated with speaker orientation, so that the temporal features in C yield the "normal" indexical value. Moreover, (34) is strengthened into a biconditional, to the effect that, whenever a representation contains the temporal coordinate of an agent, it must express the content of an attitude of that agent.

Concerning (43a), three ILFs must be considered. The first is built from C's complement, $\mathrm{XP}$ in (43a); it is interpreted under a subject-oriented assignment and reports the content of the subject's original words. The result is that the in situ copy of the present tense provides for a pregnancy that overlaps with the subject's temporal coordinate. Then we have the node $C$ itself, where the $\tau$-features are interpreted by means of the speaker-oriented assignment. The result is that the pregnancy state overlaps with the speaker's temporal coordinates as well. Finally, we have the ILF associated with the whole dominating CP, where the former two ILFs are put together in such a way that they are required to have coordinated value: whenever the one (the ILF for XP) is true, the other (the ILF for C) is true as well, and vice versa. This coordination of truth values is meant to account for the observation made above about the content of the speaker's attitude: the speaker maintains that, if Mary was pregnant at the subject's time, then the same pregnancy obtains at her time, and vice versa.

The following features of this approach should be noticed: it generalizes the idea, already discussed in section 3.2, that the content of attitude ascriptions, as expressed by ILFs, depends on the subject's coordinate (context or mental state), since it incorporates her temporal coordinates, and explicitly extends it to the speaker, by seeing 
$\mathrm{C}$ as the locus where speaker orientation comes to play a role. This approach shares with de re theories - most notably Abush's and Schlenker's -the idea that the tense is moved. However, it identifies the place where movement is directed to, namely, C, and motivates such a movement with the triggering $\tau$-features in $\mathrm{C}$. This approach is further discussed in Giorgi (2010), who considers the syntactic and interpretive relevance of the speaker's temporal location in the C-layer in several contexts - such as dependencies from future verbs and free indirect discourse contexts. The importance of a syntactic locus of indexical items - usually taken to be in the left periphery of the clause - has recently been developed by several scholars, for instance by Bianchi (2006) and by Sigurdhsson (2004).

\subsection{Temporal adverbials}

If temporal entities (times) are part of the ontology underlying natural language and reference to them proceeds the way it does with ordinary objects, we should be able to individuate the same range of referential phenomena observed in the case of ordinary phenomena. This line of investigation has already been pursued by Partee (1973), in a seminal work where she discusses the strong similarity between tenses and pronouns. Here we will consider the issue from a syntactic point of view, taking into account temporal adverbs and the recent developments in the theory of syntax. In this section we intend to show that it is possible to single out terms that make direct reference to temporal entities by behaving as the counterparts of a proper name such as John or of deictic or indexical terms such as here or that man. It should also be possible to show that the semantic and syntactic properties of such terms are similar to those of "ordinary" proper names or indexical and deictic terms.

Obvious candidates for direct reference in the temporal realm are the names of days and months, used in isolation - say, Thursday, Sunday, May. Such names can appear as expressions that fix the time of the event:

(44) a. I met him (on) Thursday.

b. John will arrive in May.

They can also play the role of subjects or direct objects:

(45) a. John spent Thursday at the seaside.

b. May was a beautiful month.

In all these cases, the reference of these expressions is indexical, crucially involving the use of the speaker's temporal coordinate. Thus Thursday in (44a) or (45a) refers to the last day of this name before the time of the utterance; in (44b) May refers to the next month of this name after the time of the utterance, and in $(45 \mathrm{~b})$ to the last one. In this respect, they constitute canonical examples of direct reference. Interestingly, they enter into syntactic configurations that have important similarities to that of proper names, as explored by Longobardi (1994). 
More precisely, Longobardi observed that, in Italian, nominal arguments must be introduced by a category $\mathrm{D}$ :

(46) Italian

a. La madre di Maria è partita.

the mother of Maria is left

'The mother of Maria has left.'

b. "Madre di Maria è partita.

mother of Maria is left

'Mother of Maria has left.'

c. È venuto Camaresi vecchio.

is come Camaresi old

'Old Camaresi came.'

d. ${ }^{*} \grave{E}$ venuto vecchio Camaresi.

is come old Camaresi

Old Camaresi came.

(Longobardi 1994, ex. 29c)

e. Bevo sempre vino.

drink-1sG always wine

'I always drink wine.'

(Longobardi 1994, ex. 12a)

This position can be occupied by an overt determiner (see (46a)), by the raised nominal head, as in (46c), or by an empty determiner, as in (46e), where a mass noun appears. Longobardi (1994) and Giorgi and Pianesi (1997) observe that names of days and names of months exhibit a similar behavior:

(47) Italian
a. Ho passato (il) giovedì scorso al mare.
have 1sG spent (the) Thursday last at the seaside
'I spent last Thursday at the seaside.'

b. Ho passato ${ }^{*}(\mathrm{lo})$ scorso giovedì al mare.

have 1sG spent (the) last Thursday at the seaside

'I spent last Thursday at the seaside.'

(48) Italian

a. (Il) giovedì scorso è passato velocemente.

(the) Thursday last is passed quickly

'Last Thursday passed quickly.'

b. (Lo) scorso giovedì è passato velocemente

(the) last Thursday is passed quickly

'Last Thursday passed quickly.'

(49) Italian

Ho passato giovedì al mare.

have-1sg spent Thursday at the seaside

'I have spent Thursday at the seaside.' 
(50)
a. Mario ha passato domenica sola al mare. Mario has spent Sunday only-FeM at the seaside 'Mario spent only Sunday at the seaside.'
b. "Mario ha passato sola domenica al mare. Mario has spent only-FEM Sunday at the seaside 'Mario spent only Sunday at the seaside.'

These examples reproduce the pattern in (46) and can be taken as evidence that the noun giovedì ('Thursday') can overtly raise to $\mathrm{D}^{0}$, as proper names do in Longobardi's theory, and for similar reasons. Thus, in (46c) and (47a), with the postnominal adjective, the definite article may be dropped, which shows that the noun has risen in the $\mathrm{D}^{0}$ position. When the adjective is prenominal, however, the article must be present, as in (46d) and (47b). Finally, (50a) and (50b) reproduce the same pattern with a non-temporal adjective, solo (only).

This discussion shows that direct reference (in the form of indexical reference) can be found in the temporal realm. Importantly, the expressions realizing it participate in the same syntactic pattern as those observed in objectual reference.

\section{A non-referential approach}

After this review of the referential approach - that is, of the idea that the interpretive properties of tenses and temporal expressions are best explained by postulating variables in the object language that refer to temporal entities - we will briefly consider theories that claim that temporal entities and temporal reference should be banned from the basic ontology and from semantics. This has been an influential view, especially in philosophy, and has recently found more than episodic links with linguistics, thanks to Ludlow (1999). The importance of this enterprise to linguistics is that it tries to show that the very basic question of whether reference to time is to be admitted or not among the tools of the theory is still an open issue and that it must be solved both by taking metaphysical concerns seriously and by comparing alternative theories on an empirical basis.

In this section we will present the basic tenets of Ludlow's theory, trying first of all to provide reasons for the move and to discuss the theory's machinery and some of its applications to the selected phenomena, which often are the same as those addressed in the review of referential approaches.

\subsection{A-series versus B-series}

Metaphysical concerns are crucial for anyone who thinks that the goal of semantic theory is to investigate the "tacit" knowledge that permits people to draw appropriate language-world connections. Such a theory is, for instance, an absolute-truth theory of semantic knowledge, of the kind we have often resorted to in this chapter: an axiomatic theory comprising axioms that give the referents of terminal symbols and rules for producing the semantic value of non-terminal nodes, starting from the former values. For the theory to make interesting claims, it must rely on some understanding of what is out there in the world, hence it cannot evade a certain 
degree of metaphysical commitment. By the same token, Ludlow argues that linguistic inquiry can in turn contribute to further the investigation of metaphysical issues.

As far as time is concerned, two metaphysical positions have stimulated the inventiveness of scholars. According to the first (which was shared by Russell, Reichenbach, and Einstein), time is a sequence of unchanging, tenseless events in which "future events, past events, and present events are all equally real" (Ludlow 1999, 1). This view is known as the B-series theory of time (McTaggart 1908) or the untensed conception of time (Mellor 1981) and is the one that underlies referential approaches to time in language. Its opposite is the A-series or tensed doctrine, which retorts that "it is fundamental to the notion of time that events, or perhaps propositions, have genuine temporal status" (Ludlow 1999, 2). In consequence, the metaphysical status of past and future events might be different, as it corresponds to different properties.

The B-series conception maintains that the basic relations are the familiar ones that can be construed from the notion of precedence and allow us to talk about an event or a time as being earlier than, later than, or simultaneous with another event or time. These notions suffice if we wish to analyze and explain away change, which is taken not to be metaphysically real but to have only a psychological status. In other words, change is apparent: events and times are given, and all we can say is that some of them precede, or are simultaneous with, some others. We do have the "feeling" of change, but, as observed, this is not metaphysically real and has no direct counterpart in the underlying ontology; in this sense, the B-series is objective.

The alternative account replies that change is metaphysically real: a past event is ontologically different from a future event, and this requires that the relation of precedence be abandoned in favor of the basic notions of past, present, and future (thus one avoids constructing the latter from the former). The consequence is that time entities with their usual ordering are not part of the underlying ontology, and the whole repertory of referential semantics, with its resources (direct reference, quantification, the traditional views of indexicality), cannot be used to account for temporal talk. For the same reasons, the A-series view is not friendly to traditional tense logic. As observed in section 3, though the latter eschew explicit talk about temporal entities from the object language, they have it in the metalanguage. The A-series conception opposes this move too; there are no time points (or intervals) in the ontology, so they cannot be manipulated at any level of the logical language.

The two opposing fields have both metaphysical and semantic facts to duel about. We will not insist on the former, on which the reader may consult Ludlow (1999) and Bonomi (2002). Concerning the latter, temporal indexicals are a case in point. Ludlow considers the situation of a person (himself, apparently) who thinks:

My fifth anniversary is March 12.

Upon discovering that the very day on which that thought occurs is March 12, he shouts:

My fifth anniversary is today! 
These two tokens exemplify one of the classic problems of indexicals. If we take a referential view of time and hypothesize that the meaning of an utterance is a tenseless (impersonal) proposition, then the two utterances above may end up having the same meaning - namely the proposition that Ludlow's anniversary is March 12. But clearly there's a difference between the kind of knowledge communicated by (51) and that pertaining to (52). Even if we admit that the two utterances have the same content or meaning - for example, that a particular event (Ludlow's anniversary) occurs at a particular time - we need to account for the cognitive difference. The latter seems to consist of the fact that, by uttering (52), the speaker acknowledges that March 12 (the day of his anniversary) is the same day as that of his utterance. The particular mood he is in is caused by this very fact, not by the (much less urgent) piece of information that his anniversary occurs at such-and-such time. A possible move suggested in the literature (e.g., Perry 1969; 1977; Kaplan 1990) is to capture the difference through the notion of the character or role of an (indexical) expression. Characters are entities that connect meanings to contexts of speech or thoughts in such a way that, given a context, the character of an indexical expression provides its meaning. In the case at hand, March 12 and today are indexical expressions (the former is taken to refer to the next day) and have different characters. The meanings (the time individuals) they provide are what enters the truth conditions of the two utterances. Larson and Segal (1995) suggest expressing this connection in the following way:

(53) a. $\operatorname{Val}(\mathrm{x}$, March 12, $\sigma)$ iff $\sigma($ March 12) $=\mathrm{x}$

b. $\operatorname{Val}(\mathrm{x}$, today, $\sigma)$ iff $\sigma($ today $)=\mathrm{u}=\mathrm{x}$

These axioms yield the following truth conditions:

(54) a. If $u$ is an utterance of 'My fifth anniversary is March 12', $s$ is the utterer of $u$, and $t$ is the time of $u$, then $u$ is true iff s's anniversary is at March 12.

b. If $u$ is an utterance of 'My fifth anniversary is today', $s$ is the utterer of $u$, and $t$ is the time of $\mathrm{u}$, then $\mathrm{u}$ is true iff s's anniversary is at $\mathrm{t}$.

It should be noted that, in a sense, characters remain outside semantics; actually they play a role in determining truth conditions, but they do so only by delivering meanings, that are used to compute truth conditions. This state of affairs has the consequence that even the differences between (51) and (52) remain beyond the reach of semantics. Indeed, the time of the utterance happens to be March 12 for both sentences, hence the truth conditions in (54) end up being the same. So, while the notion of character has some role in accounting for the different status of (51) as compared to (52), this remains outside the semantic realm.

For those who are dissatisfied with this outcome because they believe that the difference between (51) and (52) should be reflected in the semantics or in truth conditions, the possibility is open of resorting to token-reflexive truth conditions à la Reichenbach (1947), which incorporate the reference to the very utterance (thought) 
token in the truth conditions. In this case, the truth conditions for (51) and (52) are as follows:

(55) a. If $u$ is an utterance of 'My fifth anniversary is March 12 ', $s$ is the utterer of $u$, and $t$ is the time of $u$, then this utterance is true iff s's anniversary is at $t$.

b. If $u$ is an utterance of 'My fifth anniversary is today', $s$ is the utterer of $u$, and $t$ is the time of $u$, then this utterance is true iff s's anniversary is at $t$-the day of this very utterance.

Now, the right-hand sides of the truth conditions differ, for the second explicitly mentions the utterance token when spelling out the referent of the indexical, whereas the other doesn't. So it seems that we have both captured the different cognitive significance of our two utterances and managed to keep the distinction within semantics.

Successful as it may appear, however, the token-reflexive strategy has its own problems. In the first place, it is not clear how the required reference to the utterance can be introduced in the semantic machinery - a seemingly technical problem that we will not discuss here. Second, a case can be construed that causes the collapse (in Ludlow's view) of the token-reflexive strategy. The point to be made draws on observations made by Castañeda (1967) on token reflexivity applied to the first person. In the case of temporality, it turns on the truth conditions of utterances like (56a), translated as in (56b), following the token-reflexive strategy:

(56) a. There is no (spoken) language.

b. If $u$ is an utterance of 'There is no spoken language', $s$ is the utterer of $u$, and $t$ is the time of $\mathrm{u}$, then this utterance is true iff there is no spoken language at $\mathrm{t}$ the time of this very utterance.

The problem is that, although utterances of the sentence (70a) are false, they are contingently so (it might have been the case that nobody uttered anything); (56b), however, is necessarily false, because of the presence of the reference to the utterance token in the truth conditions. If we drop such a reference, however, we give up the prospect of bringing context or character within the semantics. Ludlow's conclusion is that the tension between a satisfactory account of temporal indexicality and the analysis of sentences that are about linguistic tokens, such as (56a), originates in the very resources of the B-series: time and reference to it. So attempts at getting rid of the B-series seem justified.

On the other hand, are there any reasons to prefer the B-series to the A-series? Of course there are, and we have already presented some of them when we discussed the shortcomings of temporal logic: complex tenses and anaphora are the best known and most discussed problems, not only for temporal logic but for any genuine A-series accounts. Given that the latter do not even admit temporal entities in the ontology, how can temporal anaphora be dealt with? And how can complex tenses be accounted for?

The only effective reply is to try to develop an explicit A-theory semantics. In this respect we saw that the tensed approach takes change to be real and to have a 
privileged status. How can such a primacy be captured? What does it mean to say that all we need is the notions of past, present, and future? Moreover, change must be accounted for in a non-circular way; it wouldn't help to resort to the metaphor of passing or flowing time, because such a passage or flow takes place in time. The only solution seems to be to represent being past, present, or future as properties that propositions (or proposition-like objects) have or fail to have and to conclude that change is simply the fact that a certain proposition was future, is present, and will be past. This, according to Ludlow, was Prior's (1967) position, which is often confused with the idea that there was a time at which a certain proposition was future, there is a time at which it is present, and there will be a time at which it will be past. The latter is what lies behind various attempts at capturing Prior's intuitions in tense logic; but those statements obviously fail to do justice to the untensed view of the A-series, for they admit temporal entities and reference to them, even if only at the metalanguage level. Taking Prior's idea seriously amounts therefore to requiring that past be "an indexical predicate that holds of a proposition-like object, effectively displaying the indexical sense of a past-tense morpheme" (Ludlow 1999, 97).

Consider the following axioms:
a. Val(true, [xP T YP], $\sigma)$ iff for some $x \operatorname{Val}(x, T, \sigma)$ and $x={ }_{\sigma}[] Y P[]$.
b. $\operatorname{Val}(x$, Tpast, $\sigma)$ iff $x$ was true.
c. $\operatorname{Val}(\mathrm{x}$, Tpres, $\sigma)$ iff $\mathrm{x}$ is true.
d. $\operatorname{Val}(x$, Tfut, $\sigma)$ iff $x$ will be true.

The first axiom assigns the value true to the clausal structure [xP T YP] iff the ILF of YP (a proposition-like object) is the value associated with the tense node. As in tense-logical approaches, this treatment relies on the idea that there is an appropriate representation in which the tense morpheme takes clausal scope. The contribution of the tense morpheme is in turn ruled by $(57 b)-(57 d)$, which implement the idea that tenses behave as indexical predicates of proposition-like objects. Once propositions like (57a) and (57b) are put together, we can derive the following theorem for an utterance of John left:

(58) Val(true, [XP Tpast [IP John leave]], $\sigma)$ iff ${ }_{\sigma}[] I P[]$ was true.

That is, that utterance is true iff the ILF of the IP phrase was true. To take another (well-known) example, consider utterances of the sentence My root canal is over, used to express relief after a dreadful session at the dentist (similar examples are discussed by Prior 1967, Higginbotham 1995, and others). The present theory assigns it the truth conditions in (59a), whereas the Larson and Segal-style B-series theory would yield $(59 b)$ :

(59) a. Val(true, [xp Tpast [ $\exists e(e$ is the event of my root canal)]], $\sigma)$ iff $\sigma[][\exists e(e$ is the event of my root canal)][] was true.

b. If $u$ is an utterance at $t$, by $s$ of [XP Tpast [ $\exists e(e$ is the event of my root canal)]], then Val(true, $u, \sigma)$ iff $\exists e(e$ is the event of my root canal and $e<t)$. 
As argued by many, (59b) does not explain why one can express relief by uttering that sentence: What is there to be relieved about in the fact that an event precedes a certain time (or another event)? Arguably (59a) fares better: the sense of relief stems from the fact that a given proposition (the ILF in (59a)) is past for the speaker.

Following the same path, it is possible to define axioms for other indexicals, such as yesterday or tomorrow, by treating them in the same disquotational manner as past, present, and future in (57):

(60) a. Val(true, [xP Adv YP], $\sigma)$ iff there is an $\mathrm{x}$ such that $\operatorname{Val}(\mathrm{x}, \mathrm{ADV}, \sigma)$ and $\mathrm{x}={ }_{\sigma}[]$ YP[].

b. $\operatorname{Val}(x$, yesterday/tomorrow, $\sigma)$ iff $x$ was true yesterday/will be true tomorrow.

\subsection{Complex tenses}

An important development of the theory concerns complex tenses. The account has similarities with the revised Reichenbachian analysis of Giorgi and Pianesi (1997) and others discussed in section 3.1, since it takes complex tenses to involve multiclausal constructions. Giorgi and Pianesi exploit two tense categories - T1, which is responsible for the relationship between the event time and the reference time, and $\mathrm{T} 2$, which attends to the relationship between the reference time and the speech time - and hypothesize that the clause hosting T2 is a complement of the clause where T1 lies, both being always explicit. Ludlow, on the other hand, provides LF representations for complex tenses on the basis of matrix-adjunct structures where the adjunct is a when-, before-, or after-clause that might remain implicit. Again, the axioms for the connectives rely on a disquotational treatment:

(61) a. Val(true, [s S1 when S2], $\sigma$ ) iff $\operatorname{Val}($ true, S1, $\sigma$ ) when Val(true, S2, $\sigma$ ).

b. Val(true, [s S1 before S2], $\sigma$ ) iff Val(true, S1, $\sigma$ ) before Val(true, S2, $\sigma$ ).

c. Val(true, [s S1 after S2], $\sigma$ ) iff Val(true, S1, $\sigma$ ) after Val(true, S2, $\sigma$ ).

After this it is hypothesized that all natural languages have (implicit) when-clauses whose structure is the same as that of explicit ones and whose tense is in agreement with that of the main clause.

With this in place, the syntactic structure for a pluperfect such as (61a) is as in (61b), where the past tense prefixed to the before-clause results from the requirement that the tenses of the main and adjunct clauses match:

(62) a. had left

b. Tpast[S] before Tpast[...]

Attempting a Reichenbachian analogy, the matrix clause of (62b) expresses the relationship between the event time and the speech time; the adjunct relates the reference time to the speech time, and the connectives when, before, and after take care of linking the event and the reference times. This differs in important respects from the neo-Reichenbachian analyses: the latter in fact link the reference time both to the 
event time and to the speech time, sometimes encoding such a dependence, as in Giorgi and Pianesi's (1997) morphosyntax of tenses.

The schematic LF in (62b) and the axioms given above yield the truth conditions in $(63 b)$ for the sentence in (63a):

(63) a. John had left.

b. Val(true, 'John had left', $\sigma)$ iff ${ }_{\sigma}[] \exists e($ leaving $(e) \wedge$ Agent(e, John))[] was true before ${ }_{\sigma}[][\ldots][]$ was true.

To repeat, tenses introduce indexical predicates that are treated disquotationally: what a past tense contributes is that the ILF corresponding to the de-tensed clause was true. There is no mention of times, as we would have in temporal logic (the proposition was true at a past time $=$ the (de-tensed) proposition is true at a past time). Complex tenses require implicit when-, before-, or after-clauses, temporal connectives being also treated disquotationally.

Ludlow argues that, thanks to this machinery, the theory avoids one of the commonest charges against temporal logic: the unconstrained nature of the account of complex tenses (see section 2). Contrary to what happens in temporal logic, the problem does not arise here, since complex tenses correspond not to the nesting operators but to implicit clauses introduced by appropriate temporal connectives. Operator composition is not required, hence unwanted combinations are expected not to arise. As Ludlow $(1999,124)$ puts it: "The system merely recapitulates the structure made available by the system of explicit temporal conjunctions, and inherits the constraints on that system."

At this juncture, one might object that the possibility of predicting non-existing tenses might not be completely ruled out, since temporal clauses can be nested:

(64) John left when you started to address Mary after she provoked Henry.

To the extent that the syntax of implicit when-clauses parallels that of explicit ones, nesting temporal clauses cannot be dismissed; hence the danger of overgenerating complex tenses isn't completely avoided.

As observed, the implicit temporal clauses can play the role of the Reichenbachian reference time. The latter, in turn, is a device for picking up contextually relevant times. Thus, for an utterance of John had (already) left to be felicitous, a contextually relevant time seems necessary, which plays the role of the reference time, as in the following discourse:

(65) Mary entered. John had (already) left.

This is a case of temporal anaphora, and in general the reference time has anaphoric properties.

As we know, A-series theories ban temporal reference: there are no singular propositions about times but only general ones, in the sense that none depends upon a particular temporal entity. So Ludlow accounts for the anaphoric properties of Reichenbach's reference time by deploying an E-type theory of temporal anaphora. Accordingly, (possibly implicit) temporal anaphors stand proxy for when-clauses, 
which provide the required descriptive content (for the notion of E-type anaphora, see Evans 1977). Thus, in the discourse above, the second sentence would have the LF:

\section{[[Tpast [John leave]] before TPast [...]]}

The content provided by the before-clause, in the case at hand, is something like Mary entered. Hence the resulting truth conditions are:

(67) Val(true, [[Tpast [John leave]] before Tpast[...]], $\sigma$ ) iff Val(true, [Tpast [John leave]], $\sigma$ ) before $\operatorname{Val}($ true, Tpast[...], $\sigma$ ).

Eventually the second sentence of our small discourse is uttered truthfully iff it was true that John left and this was before it was true that Mary entered. Such a strategy, it is suggested, can be generalized to all cases of temporal anaphora. If workable, it would prove that A-series approaches can handle temporal anaphora, thus replying to an important objection made by its opponents.

\subsection{Sequence of tense}

Let us briefly turn to SOT in an A-series framework:

(68) a. John said that Mary was ill.

b. [John said that [Mary was ill when [...]]]

The implicit when-clause could be taken to E-type-refer to the time of the matrix event - that is, it could be something like [when [John did the saying]] - or, as Ludlow suggests, it can be an E-type anaphora to some other contextually relevant clause, for example when John went home. The first option could then be used to account for the simultaneous reading of (68), whereas the latter might provide for the shifted reading. Such a suggestion incorporates the independent view of tenses (Dowty 1982; Abusch 1997), according to which tenses in matrix clauses behave the same way as in matrices. However, it is inadequate for the reasons discussed in section 3.2: not all past sentences will do, but only those that are not future with respect to the subject (John). So, to adopt a referential jargon, (68a) cannot be a true report of a speech of John's where he says Mary will be ill in two days.

When dealing with B-series theories, it was argued that these and other cases point to the necessity of representing the subject's (that is, the attitude's agent) coordinate in the ILF of the subordinate clause. In essence, it was said that temporal indexicality, at least as far as tenses are concerned, must be relativized to subjects. The proposal was implemented by distinguishing assignment sequences for the speaker from ones for the subject, and has the latter used for the ILF of the complement clause of propositional attitude predicates.

In the present framework, and with the present implementation of the A-series view, one might wonder whether this process of relativizing indexicals to subjects' contexts is still available. Tenses are in fact treated disquotationally, and their indexicality is not articulated anywhere but used directly. Thus, in the axiom below, 
it is the metalanguage was, on the right-hand side, that bears the burden of indexicality, being naturally interpreted as the user's (speaker's):

$\operatorname{Val}(\mathrm{x}$, Past, $\sigma)$ iff $\mathrm{x}$ was true.

On the other hand, in the cases we are interested in - say, the shifted reading of (68a) - we would like to say that both the was of the embedded clause and the tense of the implicit when-clause (or, if you prefer, the relevant perspective) are John's (the subject's). In the case of simultaneous reading (and pending an explanation of SOT), the embedded tense expresses a present tense from John's perspective, and so on. Given that, as observed, the indexicality of tenses is not articulated anywhere, it seems that the only possibility for the A-series approach to capture those intuitions consists in changing the way in which evaluation is accomplished. For instance, we could propose that the LFs of the embedded clauses of attitude reports are (or can be) evaluated by using a simulation strategy. In order to compute the correct ILF (or whatever it is that represents the content of the reported attitude), people project themselves onto, and adopt, the subject's egocentric perspective. Thus, when interpreting an utterance of sentence (68a), the speaker or hearer continues to use axiom (69); however, she does so as if she were the subject, thus turning the tense into that of the (simulated) subject. This line of thought can be extended to DAR sentences (see section 3.3). If we agree that movement of the embedded tense to the higher $\mathrm{C}$ creates two copies of the temporal features, then we can retain the idea that the first, in situ copy is evaluated in a simulative mode (as if it were the subject's), and that the other copy is evaluated in the ordinary mode (as being the speaker's). Perhaps Ludlow could subscribe to the simulation strategy applied to tenses in subordinate context. He explicitly mentions it as a possibility for indexicals in general (see Ludlow 1999, 64.)

\subsection{Taking stock of the A-series approach}

My survey of the A-series tensed theory has been very cursory, both for reasons of space and because the reference work (Ludlow 1999) is itself often cursory. Both for Ludlow and for this chapter, the goal was to show that the approach deserves to be pursued, that it can be motivated on both linguistic and non-linguistic grounds, and that, in the end, it can be compared to competing approaches by resorting to the usual notions and tools of descriptive and explanatory adequacy. Some critical observations, beyond those already provided during the discussion, can be made, nonetheless.

An important point concerns the burden that Ludlow's program places on syntax. This is a heavy one and requires more investigation before the empirical and theoretical consequences of the theory can be properly assessed. For instance, the extensive use of implicit when-, before-, and after-clauses requires that their status be better investigated and clarified. As it turns out from our survey, these clauses can be completely implicit, as in the case of complex tenses, or part of their content may be visible, as in the case of locating temporal adverbials. As for partially explicit when-clauses, one could think of adapting and extending the analysis Den Dikken, Larson, and Ludlow (1996) have proposed for intensional verbs such as seek, which 
they suggest also take (partially) implicit complement clauses. Borrowing ideas developed in their work, one might hypothesize that partially implicit when-clauses for temporal adverbials have a null verb with an underspecified semantic, so that the resulting structure would be (70), the subject also being implicit:

\section{(70) [Subj [vp V [three o'clock]]]}

One could then go on to suggest that Subj be spelled out as some measure system (the calendar, the clock, etc.), and that the implicit verb be given the following lexical axiom:

(71) $\operatorname{Val}(<\mathrm{x}, \mathrm{y}, \mathrm{e}>\mathrm{VERB}, \sigma)$ iff $\mathrm{e}$ is an event of time measurement, $\mathrm{x}$ is the measuring tool/system, and $\mathrm{y}$ is the measure.

Again, this is just a possible way to proceed, and more work is needed in order to establish it on firmer grounds. Also, the status of temporal phrases as prepositional phrases (PPs) or DPs should be considered. Perhaps expressions consisting of DPs could be integrated into the present view along the lines suggested above, as arguments of implicit verbs of implicit clauses. The move is not so straightforward for PPs, for the same (implicit) verb should select either them or DPs.

More serious difficulties are raised by temporal phrases in subject or direct object position:

(72) a. I spent Thursday/the last month/the period between May and July at the seaside.

b. May was a beautiful month.

Should one treat those expressions as part of implicit when-clauses, availing oneself of paraphrases such as (73a) for (72a) and (73b) for (72b)?

(73) a. I was at the seaside when [...Thursday...].

b. It was a beautiful month when [...May...].

Although perhaps workable for (72a), the strategy seems more difficult with (72b). For what would beautiful be predicated of? Should we resort to months, hence time, as second-order or derived entities? And, given that the latter are sets of propositions, does it make any sense to say that beautiful is predicated of (sets of ) them? The problem is even more acute in light of an example discussed by Bonomi (2002):

(74) Last Monday will be described by the newspapers as "Black Monday."

It seems impossible here to resort to the when-clause strategy; for what paraphrase based on it could do the work? And, even if this were possible, attention should be paid to ensuring that, whatever at LF corresponds to last Monday, it is not in the scope of the future tense - a problem that, as might be noted, is reminiscent of similar difficulties temporal logic approaches had in dealing with the scope interactions between the tense operator and the operators of noun phrases (see section 2). 
In the end, even if the when-clause strategy can be made to work properly for locating temporal phrases, it is hard to see what the treatment of the same expressions could be like when they appear as subjects or objects. From the point of view of linguistic theory, referential approaches have an obvious advantage over nonreferential ones here: whereas the former can treat temporal phrases uniformly, regardless of whether they serve to locate the event or function as subjects or objects, the tensed approach might end up needing to maintain an asymmetry between the two.

Turning to fully implicit clauses, they are crucial for E-type temporal anaphora. The choice here is between truly implicit (non-visible, but syntactically active) clauses and null pronouns that, in virtue of the E-type analysis, yield clausal-like contributions to the truth conditions. Ludlow explicitly considers the first alternative, speaking of LF representations at which implicit clauses are available. An important point, in this respect, is how those LF representations are built from the available material in the case of complex tenses:
a. Pluperfect: had left
Tpast[S] before Tpast[...].
b. Future perfect: will have left
c. Future: in future
Tfut[S] before Tfut [...].
Tfut[S] after Tfut[...].

According to the examples given, the main clauses contain the verb and are prefixed by a tense that seems to be the one that appears originally on the auxiliary. So, in John had left, the verb appears in the main clause, and the latter is prefixed by the past tense of the auxiliary: [S Past [S John aux leave]...]. This configuration can be obtained by letting the tense (covertly) take a wide scope and the auxiliary be interpretively inert. The participle marking on the verb seems in turn to play a role in determining the type of connective to be used: before in the case of the pluperfect tense and in that of the future perfect tense. Maybe this is due to some kind of agreement between some feature of the main verb (a tense feature, an aspectual one?) and the connective.

That this reconstruction of how LFs for complex tenses are derived is on the right track seems to be confirmed by the explicit attempt that Ludlow makes $(1999,126)$ at analyzing connectives such as before and after as the combination of a past or future tense morpheme and the connective when. The tense morpheme thus introduced takes a narrow scope, so that the LFs in (100) can be replaced by the following ones:

(76)
a. Pluperfect: had left
Tpast [Tpast [S] when [...]].
b. Future perfect: will have left
c. Future: in future
Tfut [Tpast [S] when [...]].
Tfut[Tfut $[S]$ when $[\ldots]]$.

With this, the truth conditions for John left become it was true that (it was true that John leave) when..., where the dots indicate the implicit when-clause. Note that (76) makes for a more straightforward derivation from the surface string than (75), and one that is more in line with current hypotheses about the syntax of tenses (see, e.g., Giorgi and Pianesi 1997): the tense on the auxiliary (T1) takes wide scope over the whole sentence, whereas that contributed by the past participle (T2) takes scope only over 
the main clause. Hence it seems advisable to drop (75) and directly consider (76) as a candidate for the LF representation of complex tenses.

The second strategy suggested for complex tenses has the advantage of providing an acceptable treatment of the present perfect tense. This is missing from Ludlow's inventory; if we try to fill this gap by applying the first procedure sketched above, we obtain for John has left the following LF, which is clearly wrong (contradictory, it seems):

(77) Tpres [s John leave] before Tpres [...].

If the second strategy is used (the one exploiting when-clauses, where T2 takes narrow scope over the main clause), then we have:

(78) Tpres [Tpast [John leave] when [...]].

This representation does not yield a contradiction and has truth conditions to the effect that John has left is true iff it is true that (it was true that John leave) when..., where the dots, as usual, stand for the implicit when-clause. Given that the tense with scope over the latter is the outermost present, we can conclude that John has left is true iff it was true that John leave when I speak.

This reconstruction of the present perfect is quite faithful to Reichenbach's (1947) intuition, which distinguished the present perfect from the simple past because with the former the reference time is, or overlaps with, the speech time, whereas in the latter the reference time is, or overlaps with, the event time. In the current A-series theory, the simple past introduces a when-clause in the scope of a past tense:

\section{(79) Tpast $[$ s...] when Tpast [s...]}

whereas the present perfect has a present tense when-clause (see (103)). The presence of the latter is crucial for the A-series account of the present perfect, much as the idea that the reference time is, or overlaps with, the speech time was for Reichenbach: without it, (78) would be reduced to the simple fact that it was tsrue that John leave, thus becoming very similar to (79). It should also be recalled that the first attempts at capturing the semantics of the present perfect within a tense-logical approach failed because the present perfect was analyzed as the combination Pres Past[s...], which reduce to Past $[$ s...] - this being the same representation postulated for the simple past. What those theories lacked was the acknowledgment (and means) of the role of contextual factors in tense interpretation, something stressed by Reichenbach and his followers through the use of reference time. Ludlow's tensed theory avoids this problem thanks to the device of when-clauses and E-type anaphora.

\section{Conclusion}

To conclude, it seems that the non-referential tensed approach (as worked out by Ludlow) can account for tenses in both main and subordinate clauses. The 
treatment of tenses as indexical predicates and the disquotational semantics seem to be promising both theoretically and empirically.

On the other hand, the theory has technical and conceptual problems with temporal phrases and temporal quantification. For the former, problems arise both at the syntactic level (the structure of partially implicit when-clauses) and at the semantic level (how should those phrases be analyzed when playing the role of subjects and/or objects?). With respect to temporal quantification, the idea of adopting a substitutional view is an intriguing one, and sometimes considered so by linguists too (for more on the topic, see Lewis 1985; Ludlow 1985). However, it seems that more work is necessary before non-referential theories of temporal phrases and temporal quantification can fully compete with those made available through referential approaches.

We close this chapter by briefly returning to the linguistic and semantical reasons the A-theorist has for dropping temporal reference. In section 4.1 it was argued that B-theories don't have the resources to account both for temporal indexicals and for sentences referring to linguistic tokens. One might wonder, in this connection, why that line of argument is not extended to indexicality in general, whereby the referential view for objectual talk would be rejected too. Problems similar to those discussed in section 4.1 for time indexicals are in fact found with all of the so-called essential indexicals; witness the fact that Castañeda's (1967) original observations were about the first-person pronoun. Nonetheless A-theorists do not reject objectual reference along with temporal reference. Possibly this is due to the fact that they also have philosophical reasons (which we haven't discussed) for distrusting the referential view as applied to temporal talk, so that the linguistic-semantical and the philosophical-metaphysical reasons reinforce each other. Thus linguists who might not be convinced by the above line of argument about temporal indexicals - for instance because they are willing to maintain that part of the account of indexicals should fall outside semantics - should nevertheless face the philosophical arguments. However, the linguistic-semantical reasons might gain in importance if it could be argued that the proper treatment of indexicality is actually the one suggested in section 4.1; but there is an asymmetry between temporal and objectual talk, which motivates maintaining a referential apparatus for the latter while discarding it for the former.

Perhaps such an argument can be based on the idea that indexicality seems a much more widespread and fundamental phenomenon in the temporal domain than in the objectual one. Besides tenses and such terms as yesterday, tomorrow, and the like, even three o'clock or February 15 are indexical (or, more generally, context-dependent). The only expressions that do not seem to fall within this generalization are those providing full specifications, for example April 25, 2002. These too interact with tenses, though, so that there seem to be enough reasons for maintaining that indexicality or context dependence is the rule for temporal talk. If so, the linguistic-semantic argument that Ludlow deploys could be turned toward the general conclusion that indexicality always requires a non-referential, disquotational analysis (which can be complemented with a simulationist approach to propositional attitudes: see section 4.3). Those devices (almost) exhaust the requirements of temporal talk, whereas the ubiquity of non-indexical (non-context-dependent) objectual talk justifies a referential apparatus for temporal talk, too.

SEE ALSO: Sequence of Tense; Subjunctives 


\section{References}

Abusch, Dorit. 1997. "Sequence of Tense and Temporal de re." Linguistics and Philosophy, 20: $1-50$.

Bianchi, Valentina. 2006. "On the Syntax of Personal Arguments." Lingua, 116: 2023-2067.

Bonomi, Andrea. 2002. "Review of Peter Ludlow's Semantics, Tense and Time: An Essay in the Metaphysics of Natural Language." Linguistics and Philosophy, 25: 81-95.

Castañeda, Hector-Neri. 1967. "Indicators and Quasi-Indicators." American Philosophical Quarterly, 4: 85-100.

Cinque, Guglielmo. 1999. Adverbs and Functional Heads: A Cross-Linguistic Perspective. New York, NY: Oxford University Press.

Cinque, Guglielmo, and Luigi Rizzi. 2008. "The Cartography of Syntactic Structures." In CISCL Working Papers on Language and Cognition 2, edited by Vincenzo Moscati, 43-59.

Comrie, Bernard. 1976. Aspect. Cambridge: Cambridge University Press.

Comrie, Bernard. 1985. Tense. Cambridge: Cambridge University Press.

Cresswell, Maxwell John, and Arnim von Stechow. 1982. "De re Belief Generalised." Linguistics and Philosophy, 5: 503-535.

Declerck, Renaat. 1986. "From Reichenbach (1947) to Comrie (1985) and Beyond." Lingua, 70: 305-364.

Demirdache, Hamida, and Miriam Uribe-Etxebarria. 2007. "The Syntax of Time Arguments." Lingua, 117 (2): 330-366.

Dikken, Marcel den, Richard Larson, and Peter Ludlow. 1996. "Intensional Transitive Verbs." Rivista di Linguistica, 8: 29-46.

Dowty, David. 1979. Word Meaning and Montague Grammar: The Semantics of Verbs and Times in Generative Semantics and Montague's PTQ. Dordrecht: Reidel.

Dowty, David. 1982. "Tense, Time Adverbs, and Compositional Semantic Theory." Linguistics and Philosophy, 5: 23-55.

Enç, Mürvet. 1986. “Towards a Referential Analysis of Temporal Expressions.” Linguistics and Philosophy, 9: 405-426.

Enç, Mürvet. 1987. "Anchoring Conditions for Tense." Linguistic Inquiry,18: 633-657.

Evans, Gareth. 1977. "Pronouns, Quantifiers, and Relative Clauses (I)." Canadian Journal of Philosophy, 7: 467-536.

Giorgi, Alessandra. 2010, About the Speaker: Towards a Syntax of Indexicality, Oxford: Oxford University Press.

Giorgi, Alessandra, and Fabio Pianesi. 1997. Tense and Aspect: From Semantics to Morphosyntax. Oxford: Oxford University Press.

Giorgi, Alessandra, and Fabio Pianesi. 2000. "Sequence of Tense Phenomena in Italian: A Morphosyntactic Analysis." Probus, 12: 1-32.

Giorgi, Alessandra, and Fabio Pianesi. 2001a. "Imperfect Dreams: The Temporal Dependencies of Fictional Predicates." Probus, 13: 31-68.

Giorgi, Alessandra, and Fabio Pianesi. 2001b. "Tense, Attitudes and Subjects." In Proceedings of SALT XI, edited by Rachel Hastings, Brendan Jackson, and Zsofia Zvolenszky.

Higginbotham, James. 1991. "Belief and Logic Form." Mind and Language, 6: 344-369.

Higginbotham, James. 1995. "Tensed Thoughts." Mind and Language, 10: 226-249.

Higginbotham, James. 2009. Tense, Aspect, and Indexicality. Oxford: Oxford University Press. Hornstein, Norbert. 1990. As Time Goes By. Cambridge, MA: MIT Press.

Julien, Marit. 2001. "The Syntax of Complex Tenses." Linguistic Review, 18: 125-167.

Kamp, Hans. 1968. "Tense Logic and the Theory of Linear Order." PhD diss., UCLA.

Kamp, Hans, and Uwe Reyle. 1993. From Discourse to Logic. Dordrecht: Kluwer.

Kaplan, David. 1990. “Thoughts on Demonstratives.” In Demonstratives, edited by Palle Yourgrau. Oxford: Oxford University Press. 
Larson, Richard, and Gabriel Segal. 1995. Knowledge of Meaning. Cambridge, MA: MIT Press. Lewis, David. 1979. "Attitude de dicto and de re." Philosophical Review, 88: 513-543.

Lewis, David. 1985. "Substitutional Quantification and Nonstandard Quantifiers." Noûs, 19: 447-451.

Longobardi, Giuseppe. 1994. "Reference and Proper Names: A Theory of N-Movement in Syntax and Logical Form." Linguistic Inquiry, 25: 609-665.

Ludlow, Peter. 1985. "The Syntax and Semantics of Referential Attitude Reports." PhD diss., Columbia University.

Ludlow, Peter. 1999. Semantics, Tense and Time. Cambridge, MA: MIT Press.

McTaggart, John Ellis. 1908. "The Unreality of Time." Mind, 68: 457-474.

Mellor, D. Hugh. 1981. Real Time. Cambridge, MA: MIT Press.

Montague, Richard. 1974. Formal Philosophy: Selected Papers of Richard Montague, edited by Richmond H. Thomason. New Haven, CT: Yale University Press.

Musan, Renate. 1995. "On the Temporal Interpretation of Noun Phrases." PhD diss., MIT Press, Cambridge, MA.

Ogihara, Toshiyuki. 1995. "Double-Access Sentences and Reference to States." Natural Language Semantics, 3: 177-210.

Parsons, Terence. 1990. Events in the Semantics of English: A Study in Subatomic Semantics. Cambridge, MA: MIT Press.

Partee, B. H. 1973. "Some Structural Analogies between Tenses and Pronouns in English." Journal of Philosophy, 79 (18): 601-609.

Perry, John. 1969. "The Problem of the Essential Indexical." Nô̂s, 13: 3-21.

Perry, John. 1977. “Frege on Demonstratives." Philosophical Review, 86: 474-497.

Prior, Arthur. 1967. Past, Present and Future. New York, NY: Oxford University Press.

Reichenbach, Hans. 1947. Elements of Symbolic Logic. New York, NY: Macmillan.

Schlenker, Philippe. 2003. "A Plea for Monsters." Linguistics and Philosophy, 26: 29-120.

Scorretti, Mauro. 1991. "Complementizers in Italian and Romance." PhD diss., University of Amsterdam.

Sigurdhssson, Halldór Ármann. 2004. "The Syntax of Person and Speech Features." In The Syntax and Interpretation of Person Features, edited by Valentina Bianchi and Kenneth Safir. Italian Journal of Linguistics, 16 (1): 219-251.

Smith, Carlota. 1978. "The Syntax and Semantics of Temporal Expressions in English." Linguistics and Philosophy, 79: 43-99.

Stowell, Tim. 1996. "The Phrase Structure of Tense." In Phrase Structure and the Lexicon, edited by Johan Rooryck and Laurie Zaring, 277-291. Dordrecht: Kluwer.

Stowell, Tim. 2007, "The English Konjunkiv II." In Time and Modality, edited by Jacqueline Lecarme and Jacqueline Guéron, pp. 251-272. Berlin: Springer Science and Business Media.

Tonhauser, Judith. 2015. "Cross-Linguistic Temporal Reference." Annual Review of Linguistics, 1: 129-154.

Vikner, Sten. 1985. "Reichenbach Revisited: One, Two or Three Temporal Relations?" Acta Linguistica Hafniensia, 19: 81-98.

Zagona, Karen. 1990. "Times as Temporal Argument Structure." Paper presented at the conference "Time in Language," MIT.

\section{Further readings}

Guéron, Jaqueline. 2007. “On Tense and Aspect." Lingua, 117 (2): 367-391.

Kaplan, David. 1989. "Demonstratives: An Essay on the Semantics, Logic, Metaphysics, and Epistemology of Demonstratives and Other Indexicals." In Themes from Kaplan, edited by 
Josef Almog, John Perry, and Howard Wettstein, 481-564. Oxford: Oxford University Press.

Larson, Richard. 1988. “On the Double Object Construction.” Linguistic Inquiry, 19: 335-391.

Zagona, K. 1992. "Tense-Binding and the Construal of Present Tense." In Theoretical Analyses in Romance Linguistics, edited by Christiane Laeufer and Terrell A. Morgan, 385-398. Amsterdam: John Benjamins.

Zagona, Karen. 2003. "Tense and Anaphora: Is There a Tense-Specific Theory of Coreference?" In Anaphora: A Reference Guide, edited by Andrew Barss, 140-171.

Zagona, Karen, ed. 2007. “Approaches to Tense and Tense Construal." Lingua, 117 (2). 